(2) Open Access Full Text Article

\title{
Dealing with thrombocytopenia during anticoagulation with heparins for active venous thromboembolism: a play-it-safe practical approach
}

\author{
This article was published in the following Dove Press journal: \\ Therapeutics and Clinical Risk Management \\ 13 June 201 I \\ Number of times this article has been viewed
}

\section{Hikmat Abdel-Razeq Yousef Ismael}

Section of Hematology and Medical Oncology, Department of Internal Medicine, King Hussein Cancer Center, Amman, Jordan
Correspondence: Hikmat Abdel-Razeq Chief, Section of Hematology and Medical Oncology, Chairman, Department of Internal Medicine, King Hussein Cancer Center, Amman II I94, Jordan Tel +962 65300460 , ext I000 Email habdelrazeq@khcc.jo
Purpose: Thrombocytopenia is not uncommonly encountered following active anticoagulation of thromboembolism with unfractionated or even low-molecular-weight heparins. In this report, and utilizing a case study, we will address issues related to the diagnosis and treatment of heparin-induced thrombocytopenia (HIT) in a community-based clinical practice.

Methods: The case of a 73-year-old female patient who was recently diagnosed with gastroesophageal junction cancer and who developed left lower extremity deep vein thrombosis (DVT) while on active chemotherapy is presented. Following the initiation of anticoagulation, a significant drop in platelet counts was noted and a clinical diagnosis of HIT was made. Articles published in English addressing issues related to anticoagulation and thrombocytopenia were accessed from PubMed and are discussed.

Results: HIT is not uncommon, but its diagnosis can occasionally be difficult to confirm. Alternative anticoagulants might not be available for immediate use and many require special expertise for appropriate use. Fondaparinux, a synthetic pentasaccharide, is approved for active anticoagulation of DVT and pulmonary embolism and can be given once daily subcutaneously at a fixed dose with no need for monitoring. Many recent reports described the successful use of this agent in the treatment of HIT.

Conclusion: HIT can be difficult to diagnose; diagnostic tests are generally not available in most hospitals and the available ones lack the sensitivity and specificity needed to confirm such diagnosis. Additionally, the alternative anticoagulants are not widely available. In such circumstances, fondaparinux can be used as an alternative anticoagulant.

Keywords: anticoagulation, thrombosis, thrombocytopenia, heparin-induced thrombocytopenia

\section{Case presentation}

A 73-year-old female patient with multiple medical problems, including diabetes mellitus, hypertension, ischemic heart disease, and mild congestive heart failure, was recently diagnosed with gastroesophageal junction cancer for which she was started on 5-flurouracil (5-FU) as a continuous infusion through a Hickman catheter, the patency of which was maintained by regular heparin flushes.

The patient was admitted 2 weeks after chemotherapy infusion with few days' history of progressive left calf pain and swelling. There was no associated trauma, joint pain, or fever. Physical exam confirmed left calf redness, hotness, tenderness, and swelling below the knee joint down to the ankle. A Doppler ultrasound confirmed 
a diagnosis of left lower extremity deep vein thrombosis (DVT) involving the superficial and common femoral veins. Platelet counts 1 and 2 weeks earlier were $376 \times 10^{9} / \mathrm{L}$ and $286 \times 10^{9} / \mathrm{L}$, respectively. On admission the platelet counts were $103 \times 10^{9} / \mathrm{L}$ with a normal activated partial thromboplastin time (aPTT) and international normalized ratio (INR). Patient was started on anticoagulation with unfractionated heparin (UFH).

The next day, however, platelet counts were noted to be low at $33 \times 10^{9} / \mathrm{L}$. Work up for disseminated intravascular coagulation (DIC) including blood film, fibrinogen, and D-dimer were all negative. Both aPTT and INR were within normal limits, too. Further evaluation failed to show any new venous thrombosis, progression of the old thrombus, or arterial ischemia.

A clinical diagnosis of heparin-induced thrombocytopenia (HIT) was made, though laboratory tests to confirm such diagnosis were not available. Heparin infusion was stopped and a decision was made to anticogulate with fondaparinux $7.5 \mathrm{mg}$ subcutaneously once daily. Platelet counts, which were followed daily (Figure 1), started to improve 3 days later and normalized on day 6 . The patient was discharged home on day 8 with normal counts.

\section{Discussion}

Thrombocytopenia during the course of anticoagulation with UFH or low-molecular-weight heparin (LMWH) is not an uncommon complication. Depending on its severity and underlying etiology, such thrombocytopenia can be a life- or limb-threatening complication. The patient under discussion had thrombocytopenia 13 days after UFH flushes were started through the Hickman catheter which dropped significantly a day after intravenous heparin infusion was started. Though this drop can be attributed to many factors, consumptive thrombocytopenia was less likely because of the size of the thrombus and absence of coagulopathy, but more importantly, the platelet counts started the drop even before DVT was diagnosed. The patient did not have clinical evidence or laboratory findings to support a diagnosis of DIC. The most likely cause of thrombocytopenia in this case was HIT.

HIT syndromes are of two types: type I is usually associated with early-onset thrombocytopenia (within 4 days) and usually leads to a mild decrease in platelet count (rarely $<100 \times 10^{9} / \mathrm{L}$ ). The patient typically recovers within 3 days despite continued use of heparin. Type I results from nonimmune-mediated mechanisms through direct platelet activation by heparin. This type is a benign form of HIT and is usually not associated with any major clinical sequelae. ${ }^{1}$

Type II HIT, on the other hand, is usually induced by immunologic mechanisms, and typically occurs within 4 to 14 days after exposure to heparin; however, it may occur earlier in patients previously exposed to heparin. A substantial fall in platelet count (but usually $>20 \times 10^{9} / \mathrm{L}$ ), can

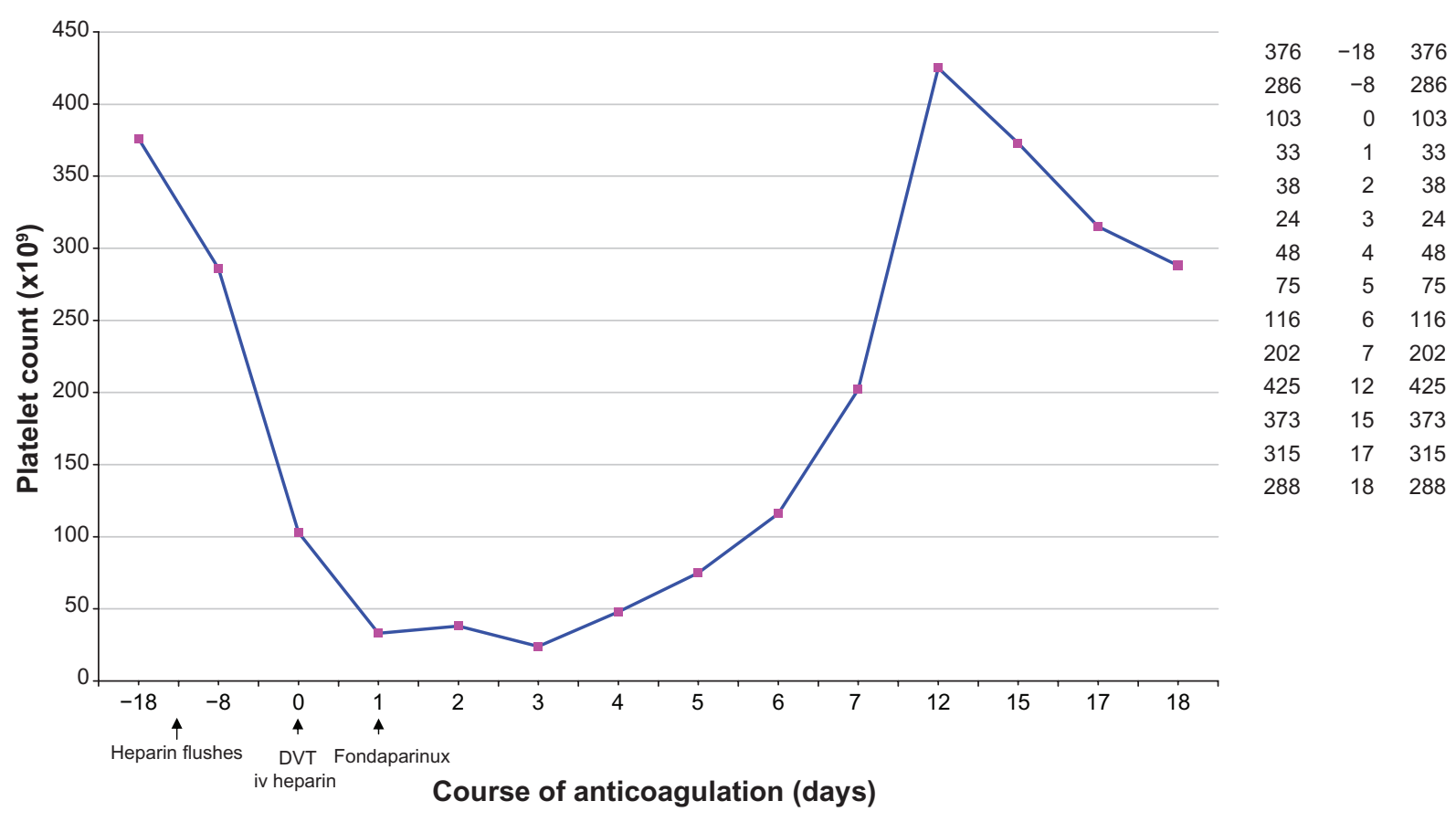

Figure I Platelet count while on anticoagulation. Abbreviation: DVT, deep vein thrombosis. 
occur with any dose, by any route, and has the potential to develop life-threatening venous or arterial thromboembolic complications that may manifest as myocardial infarction, cerebrovascular occlusion, skin necrosis, or limb ischemia. HIT tends to occur more with bovine- than porcine-derived heparin, more in females than males, and more in surgical than medical patients. ${ }^{2}$

Depending on the definition, severity of thrombocytopenia, and the form of heparin used, the frequency of HIT varies from as low as $1 \%$ to as high as $25 \%{ }^{3} \mathrm{~A}$ recent meta-analysis, however, reported a lower incidence of $2.6 \%{ }^{4}$

The diagnosis of HIT is difficult to confirm in many community hospitals. Table 1 lists some of the tests that can be used to help confirm such diagnosis; many are not available and difficult to perform. Except for the serotonin release assay, other tests lack the specificity and the sensitivity needed to establish such diagnosis.

Patients with type II HIT are at a high risk for thrombosis and should be treated with an alternative anticoagulant therapy to reduce thrombotic complications. The current treatment of choice is one of the approved direct thrombin inhibitors, argatroban, lepirudin, bivalirudin, and danaparoid (Table 2). These drugs have been proven to be safe and effective in clinical studies. ${ }^{5,6}$ However, these drugs are not widely available in community hospitals and clinical experience in their use is usually lacking. We previously encountered a more complicated case leading to limb ischemia; lacking these drugs, we reported the use of plasmapheresis to create an artificial state of anticoagulation, exchanging the patient's plasma with albumin rather than fresh frozen plasma, to allow safe introduction of warfarin. ${ }^{7}$

\section{Fondaparinux}

Fondaparinux, a synthetic pentasaccharide that specifically inhibits factor Xa activity, has been successfully used in many prophylaxis studies in medical, surgical, and patients undergoing major orthopedic procedures. ${ }^{8}$ This drug was also used in the active treatment of established venous thromboembolism (VTE). Two trials, MATISSE-DVT ${ }^{9}$ and MATISSE-PE, ${ }^{10}$ were similarly designed to demonstrate that fondaparinux was at least as effective and as safe as the current standard treatments for pulmonary embolism (PE) and DVT.

In MATTISSE-DVT, more than 2000 patients with confirmed acute symptomatic DVT were randomized to receive either a fixed once-daily dose of $7.5 \mathrm{mg}$ fondaparinux subcutaneously $(5.0 \mathrm{mg}$ in patients $<50 \mathrm{~kg}$ and $10.0 \mathrm{mg}$ in patients $>100 \mathrm{~kg}$ ) or twice-daily, weight-adjusted enoxaparin subcutaneously ( $1 \mathrm{mg} / \mathrm{kg}$ ) for at least 5 days and until anticoagulation with warfarin was therapeutic. In an intentionto-treat analysis, 43 (3.9\%) of the 1098 fondaparinux-treated patients had symptomatic recurrent thromboembolic events, compared with $45(4.1 \%)$ of the 1107 enoxaparin-treated patients (absolute difference, $-0.15 \% ; 95 \%$ CI $-1.8 \%$ to $1.5 \%){ }^{9}$

MATISSE-PE included 2213 patients presenting with symptomatic PE. In this trial, patients were randomly assigned to receive either fondaparinux $7.5 \mathrm{mg}$ subcutaneously or a dose-adjusted continuous intravenous infusion of UFH for at least 5 days. In an intention-to-treat analysis, the incidence of symptomatic recurrent VTE over the 3-month follow-up period was $3.8 \%$ in the fondaparinux group and $5.0 \%$ in the UFH group (absolute difference $-1.2 \% ; 95 \%$ $\mathrm{CI}-3 \%$ to $0.5 \%){ }^{10}$

The two MATISSE studies demonstrate that fondaparinux used at a fixed dose of $7.5 \mathrm{mg}$ once daily subcutaneously can effectively and safely treat the acute phases of both PE and DVT. This would further simplify the treatment of both DVT and PE as no bodyweight adjustment is necessary and only a single subcutaneous injection per day is required. Based on these studies, fondaparinux is now approved for the active treatment of both DVT and PE.

\section{Thrombocytopenia is not an issue with fondaparinux}

None of the clinical studies that used fondaparinux at prophylactic doses in orthopedic or general surgery, or in medical patients, or at higher doses used to treat DVT or PE, showed any significant thrombocytopenia. ${ }^{8}$

Table I Laboratory diagnosis of heparin-induced thrombocytopenia

\begin{tabular}{|c|c|c|c|}
\hline Test & Advantages & Disadvantages & Remarks \\
\hline Serotonin release assay & High sensitivity and specificity (>95\%) & $\begin{array}{l}\text { High cost } \\
\text { Technical experience }\end{array}$ & The gold-standard test \\
\hline $\begin{array}{l}\text { Heparin-induced platelet } \\
\text { aggregation assay }\end{array}$ & Specificity $>90 \%$ & Low sensitivity & \\
\hline Solid phase ELISA immunoassay & $\begin{array}{l}\text { High sensitivity: } 91 \% \text { to }>97 \% \\
\text { High negative predictive value }\end{array}$ & Low specificity: 74\%-86\% & $\begin{array}{l}\text { Test results are variable } \\
\text { in dialysis patients }\end{array}$ \\
\hline
\end{tabular}


Table 2 Anticoagulants that can be used with heparin-induced thrombocytopenia

\begin{tabular}{|c|c|c|c|c|}
\hline Drug & Brand name & Administration & Monitoring & Special issues \\
\hline Lepirudin & Refludan & $0.10 \mathrm{mg} / \mathrm{kg} / \mathrm{h}$ & aPTT ratio: $1.5-2.5$ & $\begin{array}{l}\text { Cleared by the kidney, check for dosing } \\
\text { with abnormal renal function }\end{array}$ \\
\hline Bivalirudin & Angiomax & $0.15 \mathrm{mg} / \mathrm{kg} / \mathrm{h}$ & aPTT ratio: I.5-2.5 & $\begin{array}{l}\text { Dose adjustment is needed with hepatic } \\
\text { and renal dysfunction }\end{array}$ \\
\hline Argatroban & Argatroban & $2.0 \mu \mathrm{g} / \mathrm{kg} / \mathrm{min}$ & aPTT ratio: $1.5-3.0$ & $\begin{array}{l}\text { Dose adjustment is needed with hepatic } \\
\text { but not with renal dysfunction }\end{array}$ \\
\hline Fondaparinux & Arixtra & $7.5 \mathrm{mg}$ sc daily & Not needed & Not approved by FDA for HIT \\
\hline Danaparoid & Orgaran & $\begin{array}{l}\text { Start at } 400 \text { units } / \mathrm{h} \text { for } 4 \text { hours } \\
\text { then decrease to } 300 \text { units } / \mathrm{h} \text { for } \\
4 \text { hours then } 200 \text { units } / \mathrm{h} \text { thereafter }\end{array}$ & Anti-factor Xa level & $\begin{array}{l}10 \% \text { cross reactivity with antibodies } \\
\text { responsible for HIT, cleared by the } \\
\text { kidney, long half-life }\end{array}$ \\
\hline
\end{tabular}

Abbreviations: aPTT, activated partial thromboplastin time; FDA, US Food and Drug Administration; HIT, heparin-induced thrombocytopenia.

To identify whether fondaparinux could induce platelet aggregation in a HIT-positive test system, an aggregation assay was used in which platelet-rich plasma from normal donors was mixed with fondaparinux and the serum collected from clinically symptomatic HIT-positive individuals. In this model, fondaparinux at a final concentration of $>20$ times the therapeutic concentration did not induce aggregation, whereas UFH produced a $40 \%$ to $80 \%$ aggregation response. ${ }^{11}$

In another study, Warkentin and his group tested 2726 patients for anti-PF4/heparin antibodies after they were randomized to receive antithrombotic prophylaxis with fondaparinux or LMWH (enoxaparin) following hip or knee surgery. Cross-reactivity of the $\operatorname{IgG}$ antibodies generated against PF4 in the presence of different anticoagulants, including UFH, LMWH, danaparoid, or fondaparinux, were also evaluated. The investigators found that anti-PF4/heparin antibodies were generated at similar frequencies in patients treated with fondaparinux or enoxaparin. Though antibodies reacted equally well in vitro against PF4/UFH and PF4/ $\mathrm{LMWH}$, none reacted against $\mathrm{PF} 4 /$ fondaparinux, leading to the conclusion that PF4/fondaparinux is recognized poorly by the antibodies generated, and suggesting that the risk of HIT with fondaparinux likely is very low. ${ }^{12}$

However, in at least 3 case reports, clinical HIT was seen after the use of fondaparinux, along with a strongly positive platelet serotonin release assay. ${ }^{13-15}$ Given the above, many case reports have described the successful use of fondaparinux in the management of patients with HIT. ${ }^{16-19}$

\section{Conclusions}

HIT is not uncommon. Diagnostic tests are generally not available in most hospitals and the available ones lack the sensitivity and specificity needed to confirm such diagnosis. Additionally, the alternative anticoagulants are not widely available and experience in their use is often lacking. In such circumstances, fondaparinux can be used as an alternative anticoagulant, after which warfarin can be safely introduced. Because heparins are a widely used medication and patients can be easily exposed to them, confirming such a diagnosis in a reference lab is recommended.

\section{Acknowledgment}

The authors would like to thank Ms Haifa Al-Ahmad for her support in preparing this manuscript.

\section{Disclosure}

The authors declare no conflicts of interest.

\section{References}

1. Warkentin TE. Heparin-induced thrombocytopenia:pathogenesis, frequency, avoidance and management. Drug Saf. 1997;17:325-341.

2. Warkentin TE. Venous thromboembolism in heparin-induced thrombocytopenia. Curr Opin Pulm Med. 2000;6:343-351.

3. Warkentin TE, Chong BH, Greinacher A. Heparin-induced thrombocytopenia:toward consensus. Thromb Haemost. 1998;79:1-7.

4. Martel N, Lee J, Wells PS. Risk for heparin-induced thrombocytopenia with unfractionated and low-molecular-weight heparin thromboprophylaxis: a meta-analysis. Blood. 2005;106:2710-2715.

5. Greinacher A, Eichler P, Lubenow N, Kwasny H, Luz M. Heparininduced thrombocytopenia with thromboembolic complication: metaanalysis of two prospective trials to assess the value of parenteral treatment with lepuridin and its therapeutic aPTT range. Blood. 2000;96: 846-851.

6. Alving BM. How I treat heparin-induced thrombocytopenia and thrombosis. Blood. 2003;101:31-37.

7. Abdel-Razeq H, Bajouda A, Khalil M, Ashmeg A. Treating heparininduced thrombocytopenia: the unconventional way! Saudi Med J. 2004;25:1258-1260.

8. Abdel-Razeq H. Pentasaccharides: a new class of anticoagulants in clinical practice. J Coag Dis. 2010;2:53-59.

9. Buller HR, Davidson BL, Decousus H, et al; Matisse Investigators. Fondaparinux or enoxaparin for the initial treatment of symptomatic deep venous thrombosis:a randomized trial. Ann Intern Med. 2004; 140:867.

10. The MATISSE Investigators. Subcutaneous fondaparinux versus intravenous unfractionated heparin in the initial treatment of pulmonary embolism. N Engl J Med. 2003;349:1695-1702.

11. Amiral J, Lormeau JC, Marfaing-Koka A, et al. Absence of cross-reactivity of SR90107A/Org31540 pentasaccharide with antibodies to heparinPF4 complexes developed in heparin-induced thrombocytopenia. Blood Coagul Fibrinolysis. 1997;8:114-117. 
12. Warkentin TE, Cook RJ, Marder VJ, et al. Anti-platelet factor 4/heparin antibodies in orthopedic surgery patients receiving antithrombotic prophylaxis with fondaparinux or enoxaparin. Blood. 2005;106: 3791-3796.

13. Warkentin TE, Maurer BT, Aster RH. Heparin-induced thrombocytopenia associated with fondaparinux. N Engl J Med. 2007;356:2653-2654.

14. Rota E, Bazzan M, Fantino G. Fondaparinux related thrombocytopenia in a previous low-molecular-weight heparin (LMWH)-induced heparin induced thrombocytopenia (HIT). Thromb Haemost. 2008;99:779-781.

15. Salem M, Elrefai S, Shrit M, Warkentin TE. Fondaparinux thromboprophylaxis-associated heparin-induced thrombocytopenia syndrome complicated by arterial thrombotic stroke. Thromb Haemost. 2010;104: 1071-1072.
16. Harenberg J, Jorg I, Fenyvesi T. Treatment of heparin-induced thrombocytopenia with fondaparinux. Haematologica. 2004;89:10-17.

17. Bradner J, Hallisey RK, Kuter DJ. Fondaparinux in the treatment of heparin-induced thrombocytopenia. [abstract] Blood. 2004;104:492a.

18. Kuo KH, Kovacs MJ. Successful treatment of heparin induced thrombocytopenia (HIT) with fondaparinux. [abstract] Blood. 2003; 102:319a.

19. D'Amico EA, Villaca PR, Gualandro SF, et al. Successful use of Arixtra in a patient with paroxysmal nocturnal hemoglobinuria, Budd-Chiari syndrome and heparin-induced thrombocytopenia. JThromb Haemost. $2003 ; 1: 2452$.

\section{Publish your work in this journal}

Therapeutics and Clinical Risk Management is an international, peerreviewed journal of clinical therapeutics and risk management, focusing on concise rapid reporting of clinical studies in all therapeutic areas, outcomes, safety, and programs for the effective, safe, and sustained use of medicines. This journal is indexed on PubMed Central, CAS,
EMBase, Scopus and the Elsevier Bibliographic databases. The manuscript management system is completely online and includes a very quick and fair peer-review system, which is all easy to use. Visit http://www.dovepress.com/testimonials.php to read real quotes from published authors.

Submit your manuscript here: http://www.dovepress.com/therapeutics-and-clinical-risk-management-journal 